\title{
Preparation of a Poly(L-lactide-co-caprolactone) Copolymer Using a Novel Tin(II) Alkoxide Initiator and its Fiber Processing for Potential Use as an Absorbable Monofilament Surgical Suture
}

\author{
SUJITRA RUENGDECHAWIWAT ${ }^{1}$, JINTANA SIRIPITAYANANON ${ }^{1}$, ROBERT MOLLOY $^{1,2}$, \\ RUNGLAWAN SOMSUNAN ${ }^{1}$, PAUL D. TOPHAM ${ }^{3}$, and BRIAN J. TIGHE ${ }^{3}$
}

${ }^{1}$ Biomedical Polymers Technology Unit, Department of Chemistry, Faculty of Science, Chiang Mai University, Chiang Mai 50200, Thailand

${ }^{2}$ Materials Science Research Center, Faculty of Science, Chiang Mai University, Chiang Mai 50200, Thailand

${ }^{3}$ Department of Chemical Engineering and Applied Chemistry, School of Engineering and Applied Science, Aston University, Birmingham B4 7ET, UK

Address correspondence to: Robert Molloy, Department of Chemistry, Faculty of Science, Chiang Mai University, Chiang Mai 50200, Thailand. E-mail: robert.m@cmu.ac.th

\begin{abstract}
A poly(L-lactide-co-caprolactone) copolymer, $\mathrm{P}(\mathrm{LL}-\mathrm{co}-\mathrm{CL})$, of composition 75:25 mol \% was synthesized via the bulk ring-opening copolymerization of L-lactide and $\varepsilon$-caprolactone using a novel bis[tin(II) monooctoate] diethylene glycol coordination-insertion initiator, OctSn-OCH $\mathrm{CH}_{2} \mathrm{OCH}_{2} \mathrm{CH}_{2} \mathrm{O}-\mathrm{SnOct}$. The $\mathrm{P}(\mathrm{LL}-\mathrm{co}-\mathrm{CL})$ copolymer obtained was characterized by a combination of analytical techniques, namely: nuclear magnetic resonance spectroscopy, gel permeation chromatography, dilute-solution viscometry, differential scanning calorimetry and thermogravimetric analysis. For processing into a monofilament fiber, the copolymer was melt spun with minimal draw to give a largely amorphous and unoriented as-spun fiber. The fiber's oriented semi-crystalline morphology, necessary to give the required balance of mechanical properties, was then developed via a sequence of controlled off-line hot-drawing and annealing steps. Depending on the final draw ratio, the fibers obtained had tensile strengths in the region of 200-400 MPa.
\end{abstract}

Keywords: L-Lactide, caprolactone, poly(L-lactide-co-caprolactone), ring-opening polymerization, tin(II) alkoxide, melt spinning, monofilament fiber, surgical suture 


\section{Introduction}

For many years now, biodegradable polyesters have found use in a wide range of biomedical applications such as surgical sutures, bone fixation devices, drug delivery matrices, nerve guides and scaffolds for tissue engineering [1-3]. After serving their intended purpose, they are gradually broken down by hydrolysis and the degradation products eliminated via the body's normal biological processes. Synthetic polymers have the advantage over natural polymers in that their microstructures can be tailored over a wide range of compositions in order to meet the specific requirements of a given application.

Poly(L-lactide) (PLL), or poly(lactic acid) (PLA) as it is more commonly known, is the most widely documented biodegradable polyester [4]. However, the properties of PLL by itself as a homopolymer are often found to be unsuitable for certain biomedical applications. For example, PLL is too stiff and springy to be used as a monofilament suture due to its high glass transition temperature $\left(\mathrm{T}_{\mathrm{g}}\right)$ of around $60^{\circ} \mathrm{C}$. Consequently, L-lactide is often copolymerized with one or more other cyclic ester monomers in order to produce a copolymer with the required balance of properties. Typical examples are co- and terpolymers of L-lactide, glycolide (G) and caprolactone (CL) where the G content increases the rate of absorption and the CL content increases flexibility [5-12].

An important factor in the ring-opening polymerization (ROP) of cyclic esters is the choice of initiator. Tin(II) 2-ethylhexanoate, otherwise known as tin(II) octoate or stannous octoate, $\mathrm{Sn}(\mathrm{Oct})_{2}$, has been the most commonly used initiator either by itself or more commonly in combination with an alcohol $\mathrm{ROH}$ as a co-initiator. However, it is now widely accepted that, when used in combination, the $\mathrm{Sn}(\mathrm{Oct})_{2}$ and $\mathrm{ROH}$ react together in situ to generate a tin(II) monoalkoxide, OctSnOR, and/or dialkoxide, $\mathrm{Sn}(\mathrm{OR})_{2}$, which are the true initiating species [13-16]. Both initiation and propagation occur via coordination-insertion of the monomer into the Sn-OR bond of the initiator. Although effective and convenient to use, 
a disadvantage of the $\mathrm{Sn}(\mathrm{Oct})_{2} / \mathrm{ROH}$ initiating system is that the alkoxide species are generated in situ in uncertain concentrations which in turn introduces a degree of unpredictability into the final polymer molecular weight that is obtained.

Although $\mathrm{P}(\mathrm{LL}-\mathrm{co}-\mathrm{CL})$ copolymers have been reported in the literature for use in a wide range of biomedical applications, relatively little attention has been paid to absorbable sutures, possibly because of their slow rate of absorption (typically 6-12 months) in the human body. However, in other applications where slow absorption is required, such as long-term drug delivery systems [17], barrier membranes [18], nerve guides [19,20], bioadhesives [21] and scaffolds for tissue engineering [22-24], P(LL-co-CL) copolymers have been shown to be effective and versatile materials which can be tailored through their composition to meet the specific property requirements of a given application. This paper now describes the synthesis, characterization and fiber processing of a P(LL-co-CL) copolymer for potential use as an absorbable monofilament surgical suture.

Compared with what has been previously reported, there are two aspects to the novelty of this work. Firstly, in the synthesis step, the true alkoxide initiator from the tin(II) octoate and diethylene glycol, $\mathrm{Sn}(\mathrm{Oct})_{2} / \mathrm{DEG}$, initiating system was prepared separately so that it could be isolated and then used in an accurately known concentration rather than generated in situ. Secondly, for fiber processing, the melt spinning, hot-drawing and annealing steps were conducted separately in a multi-step process rather than combined in a continuous process. The advantages of doing this were that it allowed more control over the development of fiber morphology (molecular orientation, degree of crystallinity) while, at the same time, allowing the changes to be monitored after each step until the required balance of mechanical properties (strength and flexibility) was obtained. Thus, the underlying theme of this work, bearing in mind the stringent property requirements of a monofilament surgical suture, has been to try to control both the chemical and physical microstructure of the 
copolymer and its fiber at each stage of preparation. In this way, the process as a whole could be relied upon to yield, both predictably and reproducibly, a final product with the required properties.

\section{Experimental}

\subsection{Materials}

L-Lactide was synthesized from L-lactic acid (Grand Chemical Far East Ltd., 88\%) and purified by repeated recrystallization from ethyl acetate. After drying to constant weight in a vacuum oven at $55^{\circ} \mathrm{C}$, pure L-lactide was obtained as a white crystalline solid with a chemical purity $\geq 99.5 \%$ (from DSC purity analysis). Commercial $\varepsilon$-caprolactone (Acros, 99\%) was purified by vacuum distillation over calcium hydride. Tin(II) octoate (SigmaAldrich, 95\%) and diethylene glycol (Sigma-Aldrich, $\geq 99.5 \%$ ) were each purified by heating with stirring under vacuum in order to remove octanoic acid and moisture impurities respectively.

\subsection{Instrumental Methods}

Structural analysis was carried out using a Bruker Tensor 27 Fourier-Transform Infrared (FTIR) Spectrometer over the wavelength range of 4000-400 $\mathrm{cm}^{-1}$ and a Bruker Avance Nuclear Magnetic Resonance (NMR) Spectrometer operating at field frequencies of $400 \mathrm{MHz}$ for ${ }^{1} \mathrm{H}$ NMR and $100 \mathrm{MHz}$ for ${ }^{13} \mathrm{C}-\mathrm{NMR}$.

Thermal analysis was carried out using a Perkin-Elmer DSC7 Differential Scanning Calorimeter $\left(0-200^{\circ} \mathrm{C}\right.$, heating rate $\left.10^{\circ} \mathrm{C} / \mathrm{min}\right)$ and a Perkin-Elmer TGA7 Thermogravimetric Analyzer $\left(50-500^{\circ} \mathrm{C}\right.$, heating rate $\left.20^{\circ} \mathrm{C} / \mathrm{min}\right)$. 
Copolymer molecular weight determination was performed using a Varian PL-GPC 50 Plus Gel Permeation Chromatograph (THF solvent, $40^{\circ} \mathrm{C}$, flow-rate $1 \mathrm{ml} / \mathrm{min}$ ) calibrated with narrow molecular weight distribution polystyrene standards. For comparison, intrinsic viscosity measurements in chloroform at $30^{\circ} \mathrm{C}$ were also carried out using a Schott-Geräte AVS300 Automatic Viscosity Measuring System.

Fiber processing was carried out using a Small-Scale Melt Spinning Apparatus (Ventures \& Consultancy Bradford Ltd., Bradford, UK) which could process as little as $20 \mathrm{~g}$ of material. Tensile testing of the fibers was performed using a Lloyds LRX+ Universal Mechanical Testing Machine in accordance with the test method described in the European Pharmacopoeia 5.0 for synthetic absorbable monofilament sutures [25].

\subsection{Initiator Synthesis}

The novel bis[tin(II) monooctoate] diethylene glycol initiator, OctSn-DEG-SnOct, was prepared via the reaction between $\mathrm{Sn}(\mathrm{Oct})_{2}$ and diethylene glycol (DEG), as shown in equation (1). The reaction was carried out at $130^{\circ} \mathrm{C}$ for $3 \mathrm{hrs}$ under vacuum. The lower boiling point octanoic acid (2-ethylhexanoic acid, OctH) by-product was driven off as it was formed, thereby enabling the reaction to proceed towards completion, as confirmed by FT-IR via the disappearance of the broad O-H peak of DEG. The OctSn-DEG-SnOct initiator was obtained as a pale yellow, slightly viscous liquid.

$\begin{array}{lccc}2 \mathrm{Sn}(\mathrm{Oct})_{2}+\mathrm{HOCH}_{2} \mathrm{CH}_{2} \mathrm{OCH}_{2} \mathrm{CH}_{2} \mathrm{OH} & \rightarrow \text { OctSn-OCH} \mathrm{CH}_{2} \mathrm{OCH}_{2} \mathrm{CH}_{2} \mathrm{O}-\mathrm{SnOct} & +2 \mathrm{OctH} \\ \text { tin(II) octoate } & \text { DEG } & \text { OctSn-DEG-SnOct } & \text { octanoic acid }\end{array}$

However, when the OctSn-DEG-SnOct structure in equation (1) is rearranged so that the $\mathrm{Sn}$ atom is in the middle flanked by DEG groups, as in DEG-Sn-DEG, a completely 
different initiator product is obtained. In this work, this DEG-Sn-DEG initiator was synthesized following the original method of Morrison and Haendler [26], as shown in equation (2). After separation from the hydrochloride by-product and purification, it was obtained as a white solid compound which, in common with tin(II) alkoxides of the general formula $\mathrm{Sn}(\mathrm{OR})_{2}$, was difficult to dissolve and apparently infusible due to its molecular aggregation, as represented in equation (3).

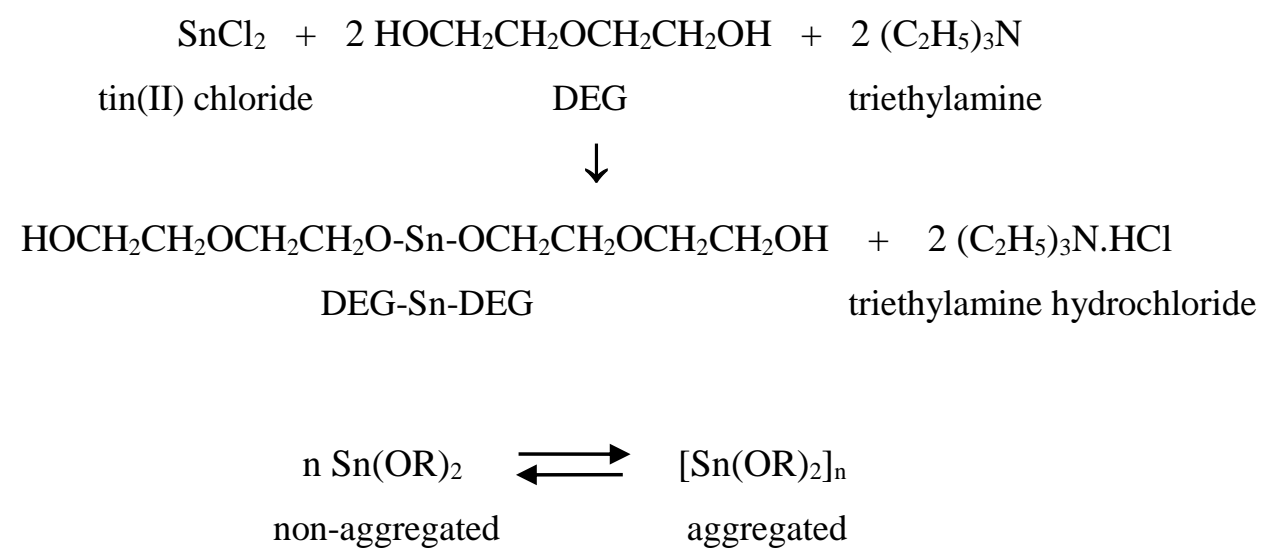

The well-documented solid-state molecular aggregation of $\mathrm{Sn}(\mathrm{OR})_{2}$-type compounds is the main drawback to their direct use as initiators in the ROP of cyclic esters [15,26-29]. Their difficult solubility in cyclic ester monomers and organic solvents leads to complicated polymerization kinetics. The final polymer molecular weights are also unpredictable since the active site (Sn-OR bond) concentration constantly changes with deaggregation and/or solubilization of the initiator. Consequently, in this present work, primary interest was focused on the soluble liquid OctSn-DEG-SnOct initiator for copolymerization purposes.

\subsection{Copolymer Synthesis}

Poly(L-lactide-co-caprolactone), P(LL-co-CL), statistical copolymers were synthesized in bulk at $130^{\circ} \mathrm{C}$ for $48 \mathrm{hrs}$ under nitrogen using OctSn-DEG-SnOct initiator concentrations of 
0.01 and $0.02 \mathrm{~mol} \%$. An initial comonomer mole ratio of LL:CL $=75: 25 \mathrm{~mol} \%$ was used since earlier work had shown that, compared with PLL, a P(LL-co-CL) 75:25 copolymer would have a sufficiently lower $\mathrm{T}_{\mathrm{g}}$ in the region of $20-30^{\circ} \mathrm{C}$ due to the flexibilizing effect of the CL and yet would still be crystallizable despite the increased structural irregularity [30]. The copolymers were purified by cutting into small pieces before heating under vacuum at $55^{\circ} \mathrm{C}$ to constant weight. Percent yields were around $95 \%$ which was consistent with the expected levels of residual monomer from theoretical equilibrium monomer concentration calculations. The comonomer and copolymer structures are shown in Figure 1.

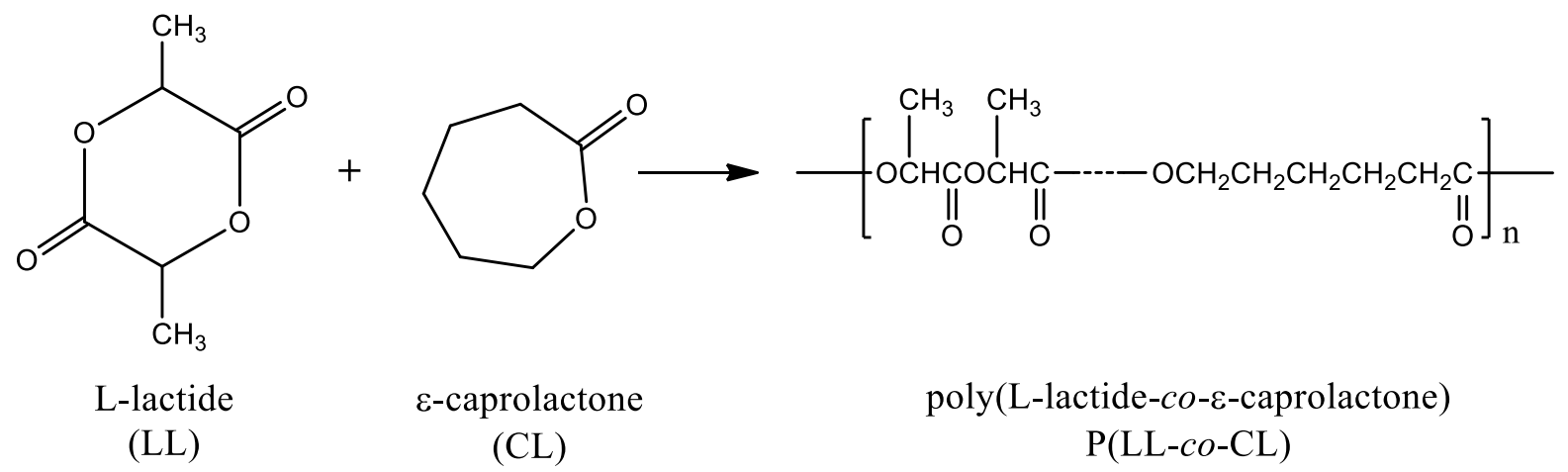

Fig. 1. Ring-opening copolymerization of L-lactide and $\varepsilon$-caprolactone.

\subsection{Fiber Processing}

The P(LL-co-CL) copolymers were melt spun into monofilament fibers using the small-scale melt spinning apparatus shown in the schematic diagram in Figure 2. Prior to melt spinning, the copolymer pieces were compressed in the cylinder into pre-formed rods at $140-145^{\circ} \mathrm{C}$ in order to remove any entrapped air which might otherwise have created voids in the extruded fiber. Melt spinning was then carried out from these rods within the temperature range of $155-165^{\circ} \mathrm{C}$ depending on the copolymer molecular weight and hence the melt viscosity. 
Using a $1 \mathrm{~mm}$ diameter single circular hole spinneret in combination with fast cooling and minimal draw, as-spun fibers were obtained which were largely amorphous and unoriented. The purpose of this was so that the required semi-crystalline, oriented morphology could be gradually built into the fibers through a series of controlled off-line hot-drawing and annealing steps. Apart from enabling greater morphological control, this multi-step procedure also had the advantage of allowing the effects of each individual step to be monitored in real time via tensile testing.

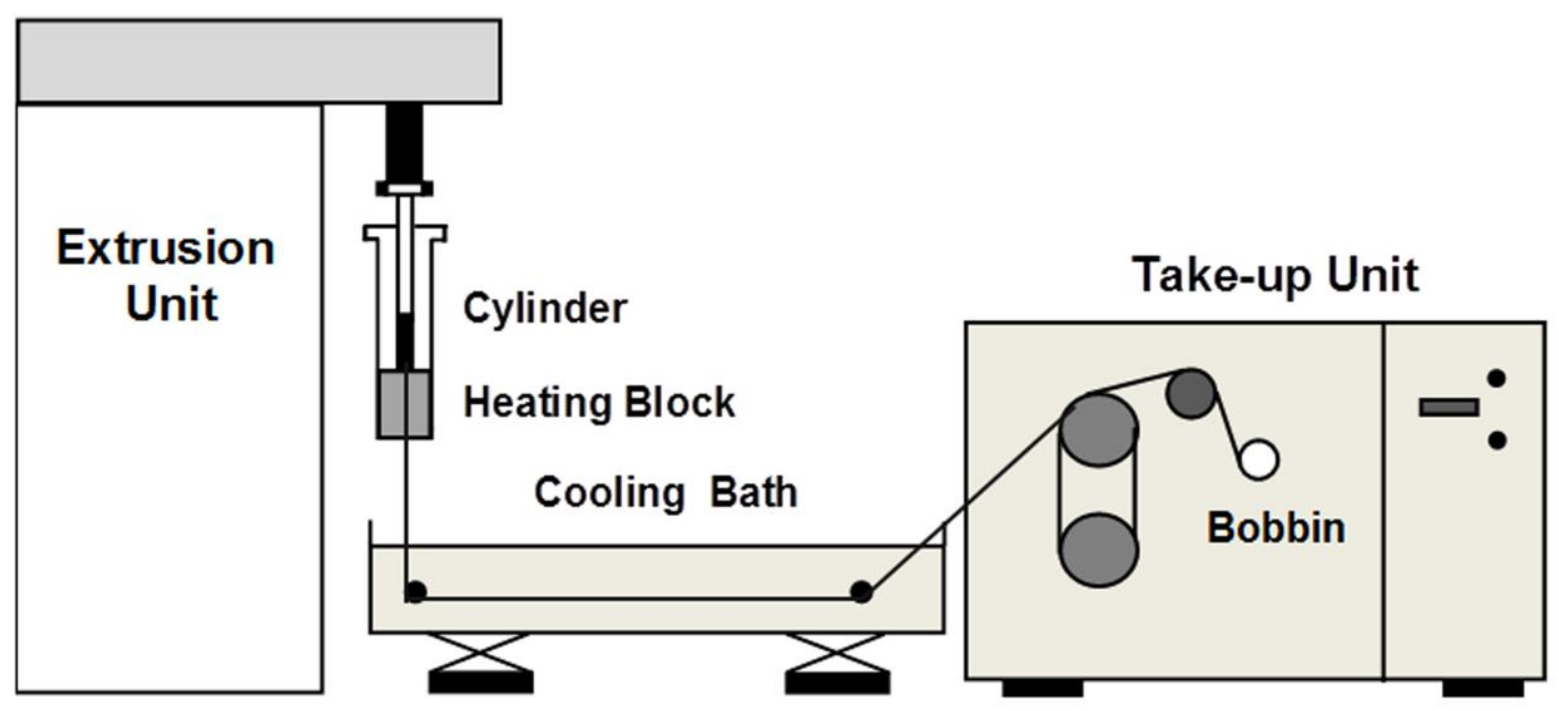

Fig. 2. Small-scale melt spinning apparatus used to produce monofilament fibers.

\section{Results and Discussion}

\subsection{Initiator Characterization}

The FT-IR spectra of $\mathrm{Sn}(\mathrm{Oct})_{2}$, DEG and the OctSn-DEG-SnOct liquid initiator are compared in Figure 3. In the initiator spectrum in Figure 3(c), the disappearance of the broad $\mathrm{O}-\mathrm{H}$ (alcohol) and $\mathrm{O}-\mathrm{H}$ (carboxylic acid) peaks in the region above $3000 \mathrm{~cm}^{-1}$ confirms the complete reaction of the DEG and the efficient removal of the octanoic acid by-product 
respectively. Otherwise the various peaks, like those in its ${ }^{1} \mathrm{H}-\mathrm{NMR}$ spectrum in Figure 4, are consistent with the OctSn-DEG-SnOct chemical structure.

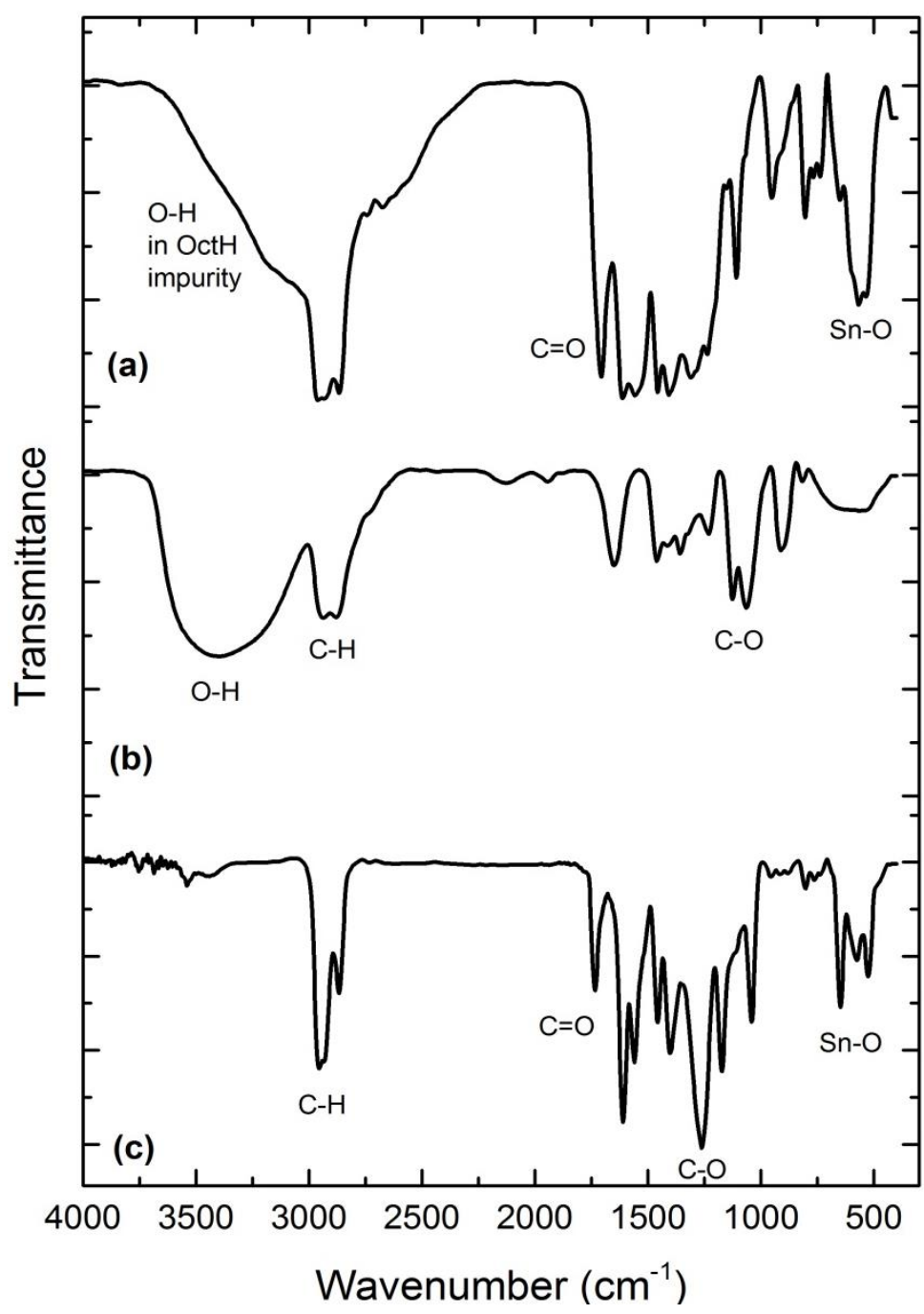

Fig. 3. FT-IR spectra of (a) Sn(Oct)2, (b) DEG and (c) the OctSn-DEG-SnOct liquid initiator. 

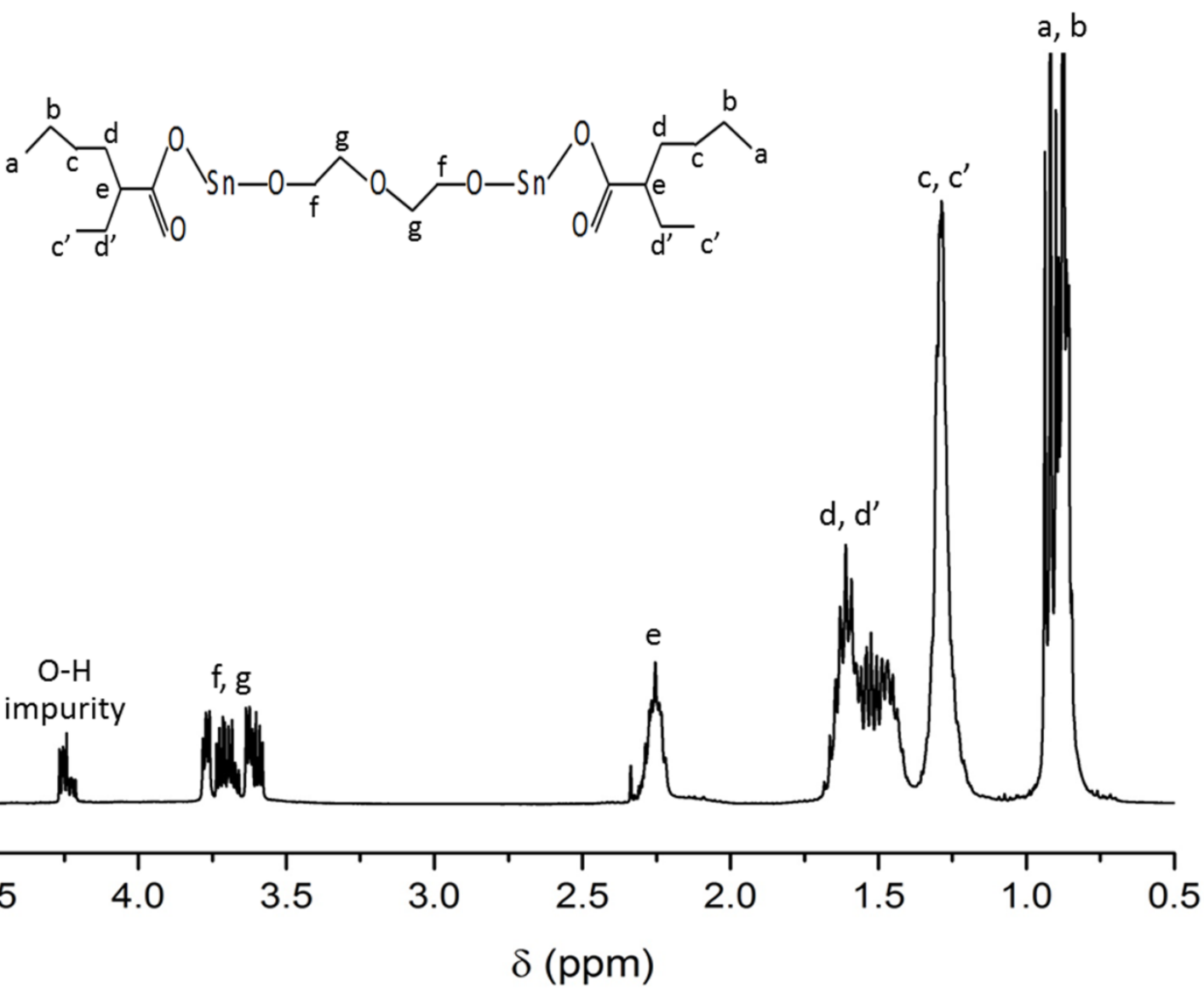

Fig. 4. $400 \mathrm{MHz}{ }^{1} \mathrm{H}-\mathrm{NMR}$ spectrum of OctSn-DEG-SnOct in $\mathrm{CDCl}_{3}$ as solvent.

In contrast to the well-resolved spectra of the liquid initiator, the FT-IR and ${ }^{1} \mathrm{H}-\mathrm{NMR}$ spectra of the solid DEG-Sn-DEG initiator, as shown in Figures 5 and 6, show peaks and resonances of relatively lower intensity and resolution due to the solid initiator's molecular aggregation and limited solubility. Despite this, Figures 5 and 6 are still seen to be consistent with the DEG-Sn-DEG chemical structure with the broad $\mathrm{O}-\mathrm{H}$ peak in Figure 5 confirming the presence of the $\mathrm{OH}$ end-groups of the DEG substituents. 


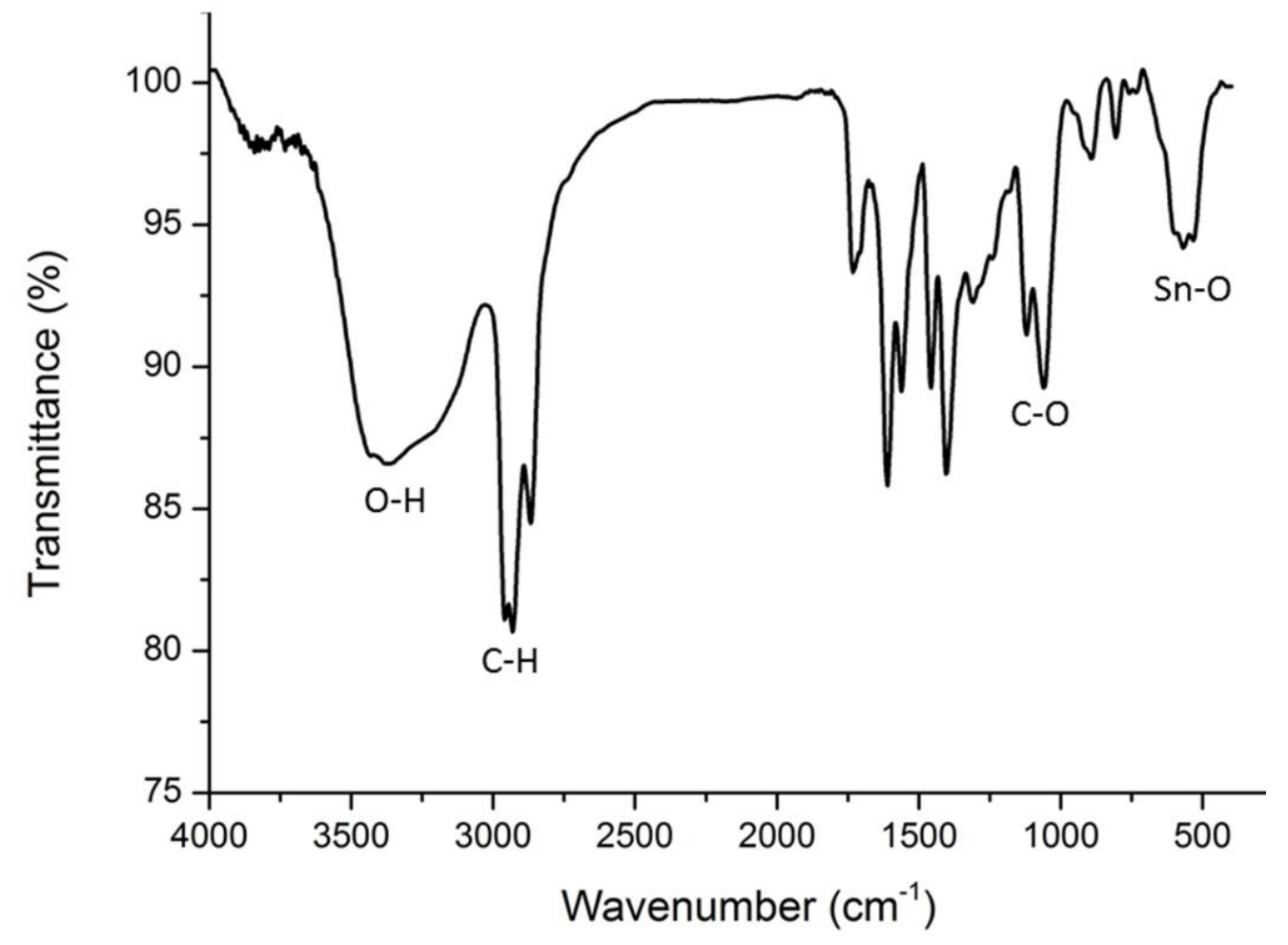

Fig. 5. FT-IR spectrum of the DEG-Sn-DEG solid initiator.

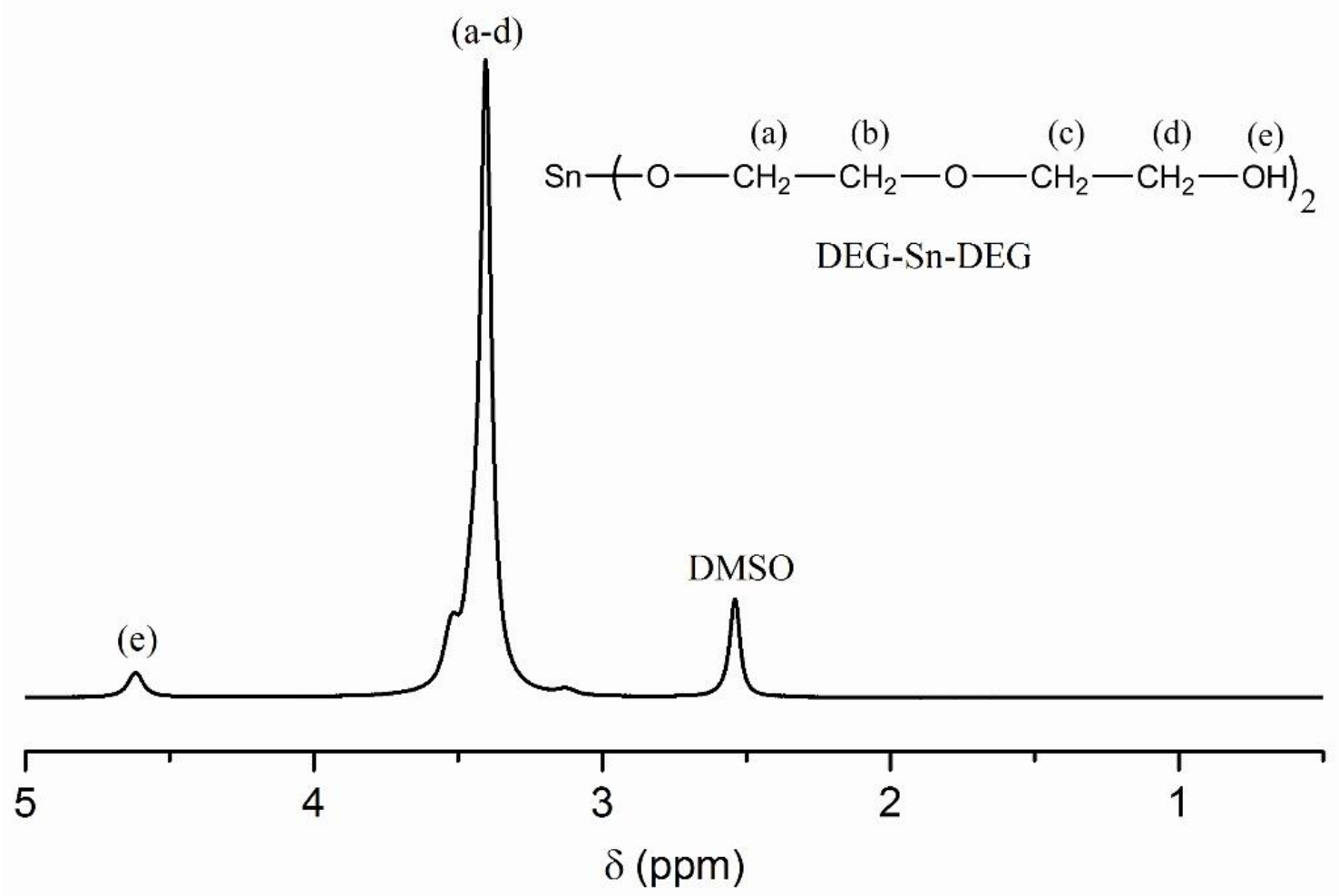

Fig. 6. $400 \mathrm{MHz}{ }^{1} \mathrm{H}-\mathrm{NMR}$ spectrum of DEG-Sn-DEG in $\mathrm{d}_{6}$-DMSO as solvent. 


\subsection{Copolymer Characterization}

\subsubsection{Composition and Monomer Sequencing}

Copolymer composition and monomer sequencing were characterized by ${ }^{1} \mathrm{H}-\mathrm{NMR}$ and ${ }^{13} \mathrm{C}$ NMR respectively. The ${ }^{1} \mathrm{H}-\mathrm{NMR}$ spectrum of an OctSn-DEG-SnOct-initiated copolymer is shown in Figure 7 as an example. The copolymer composition was calculated from the peak area integrations of the LL methine proton peak (b) at $\delta 5.2$ and the CL $\varepsilon$-methylene peak (c) at $\delta 4.1-4.2$. Since all of the copolymers were obtained in near-quantitative yields $(\approx 95 \%)$, their compositions are very similar to their initial comonomer feeds, as shown in Table 1.

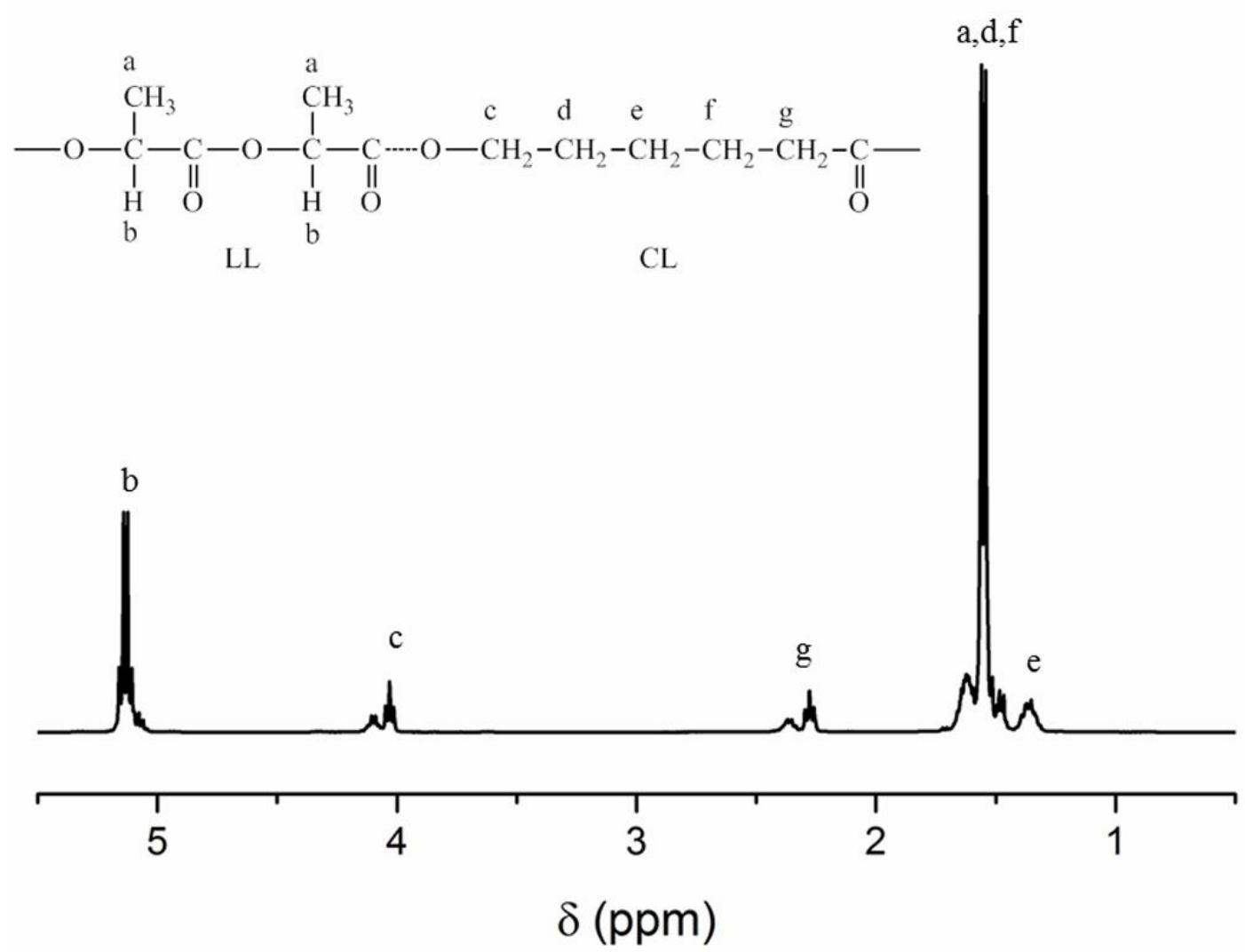

Fig. 7. $400 \mathrm{MHz}{ }^{1} \mathrm{H}-\mathrm{NMR}$ spectrum of an OctSn-DEG-SnOct-initiated P(LL-co-CL) copolymer recorded in $\mathrm{CDCl}_{3}$ as solvent. 
Monomer sequencing in the $\mathrm{P}(\mathrm{LL}-\mathrm{co}-\mathrm{CL})$ copolymers was characterized from their ${ }^{13} \mathrm{C}-\mathrm{NMR}$ spectra, specifically from the expanded carbonyl carbon $(\mathrm{C}=\mathrm{O})$ region from $\delta=$ 169-174 ppm, as shown in Figure 8 as an example. The heterotriad peaks in between the CCC and LLL homotriad peaks are a measure of the degree of randomness of the monomer sequencing. In the triad notations, $\mathrm{C}$ represents a caprolactone (CL) unit while $\mathrm{L}$ represents half a lactide (LL) unit. For example, the LCL triad sequence corresponds to:<smiles>COC(C)C(=O)OCCCCC[14C](=O)OC(C)C(C)=O</smiles>

and its peak in the spectrum is that of the central carbonyl carbon $\left(^{*}\right)$.

The fact that the LLL peak in Figure 8 is so much more prominent than the rest is a reflection of not only the higher LL content but also that the monomer sequencing is tapered (i.e., partly blocky) rather than random. This is a direct consequence of the much different reactivity ratios (LL > $>\mathrm{CL}$ ) of the L-lactide and $\varepsilon$-caprolactone comonomers. Earlier work reported reactivity ratios $(r)$ of $r_{L L}=34.7$ and $r_{C L}=0.24$ for the LL-CL bulk copolymerization at $130^{\circ} \mathrm{C}$ using $\mathrm{Sn}(\mathrm{Oct})_{2}$ as the initiator [31]. Thus, L-lactide polymerizes much faster than $\varepsilon$-caprolactone, thereby producing a final copolymer which is initially proportionately rich in LL before tapering off towards the end to become proportionately rich in CL. However, the resultant blockiness is offset to a certain extent by transesterification reactions during copolymerization which tend to randomize the monomer sequencing. 


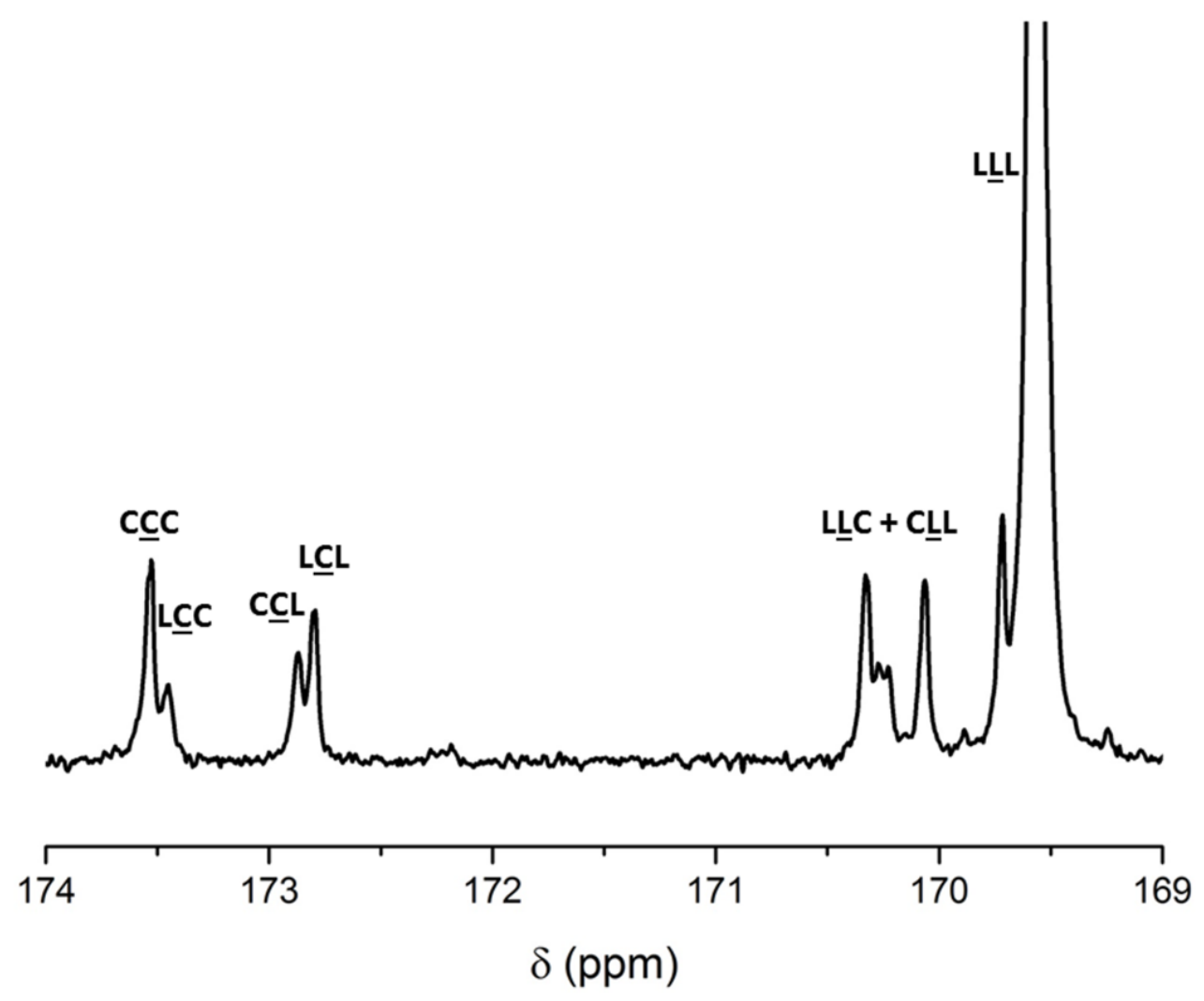

Fig. 8. Expanded carbonyl region of the ${ }^{13} \mathrm{C}-\mathrm{NMR}$ spectrum of an OctSn-DEG-SnOctinitiated $\mathrm{P}(\mathrm{LL}-\mathrm{co}-\mathrm{CL})$ copolymer recorded in $\mathrm{CDCl}_{3}$ as solvent.

Note: each peak is that of the carbonyl carbon of the central unit (underlined)

Although the large difference in monomer reactivities has the disadvantage of yielding a final product which contains a wide range of compositions, it has the advantage of producing longer LL sequences than if the sequencing was less blocky and more random. This is influential in the wider context of this work since LL is the main crystallizable component in the copolymer [32]. Thus, longer LL sequence lengths become important from the point of view of enhancing the copolymer's crystallizability and, in doing so, improving its mechanical properties when processed in the form of a monofilament fiber. 
Table 1. Comparison of the copolymer compositions, number-average, $\overline{\mathrm{M}}_{\mathrm{n}}$, and weightaverage, $\overline{\mathrm{M}}_{\mathrm{w}}$, molecular weights, polydispersities, $\mathrm{PD}$, and intrinsic viscosities, [ $\left.\eta\right]$, of the $\mathrm{P}\left(\mathrm{LL}-\mathrm{co}\right.$-CL) copolymers using OctSn-DEG-SnOct and $\mathrm{Sn}(\mathrm{Oct})_{2}$ as the initiators at different concentrations.

\begin{tabular}{|c|c|c|c|c|c|c|}
\hline Initiator & $\begin{array}{l}\text { Initiator } \\
\text { Conc. } \\
(\operatorname{mol} \%)\end{array}$ & $\begin{array}{c}\text { Copolymer } \\
\text { Composition }^{a} \\
\text { LL:CL }(\operatorname{mol} \%)\end{array}$ & $\overline{\mathrm{M}}_{\mathrm{n}}$ & $\overline{\mathrm{M}}_{\mathrm{w}}$ & $\frac{\mathrm{PD}}{\overline{\mathrm{M}}_{\mathrm{w}} / \overline{\mathrm{M}}_{\mathrm{n}}}$ & $\begin{array}{l}{[\eta]^{b}} \\
(\mathrm{dl} / \mathrm{g})\end{array}$ \\
\hline$[\mathrm{Sn}(\mathrm{Oct})]_{2} \mathrm{DEG}$ & 0.01 & $76: 24$ & $6.48 \times 10^{4}$ & $1.21 \times 10^{5}$ & 1.87 & 1.66 \\
\hline$[\mathrm{Sn}(\mathrm{Oct})]_{2} \mathrm{DEG}$ & 0.02 & $75: 25$ & $4.09 \times 10^{4}$ & $7.48 \times 10^{4}$ & 1.83 & 1.24 \\
\hline $\mathrm{Sn}(\mathrm{Oct})_{2}$ & 0.01 & $76: 24$ & $3.86 \times 10^{4}$ & $7.80 \times 10^{4}$ & 2.02 & 1.23 \\
\hline $\mathrm{Sn}(\mathrm{Oct})_{2}$ & 0.02 & $77: 23$ & $1.77 \times 10^{4}$ & $3.45 \times 10^{4}$ & 1.95 & 1.21 \\
\hline
\end{tabular}

${ }^{a}$ As determined from the ${ }^{1} \mathrm{H}-\mathrm{NMR}$ spectrum

${ }^{b}$ As determined in chloroform as solvent at $30^{\circ} \mathrm{C}$

\subsubsection{Molecular Weight Determination}

Copolymer molecular weights and polydispersities from GPC and intrinsic viscosities from dilute-solution viscometry are shown in Table 1. When compared with the conventional $\mathrm{Sn}(\mathrm{Oct})_{2}$ initiator at the same concentrations, the OctSn-DEG-SnOct initiator gave significantly higher molecular weights and lower polydispersities. Previous work has shown that for copolymers of this type to be melt spinnable into monfilament fibers that can be hotdrawn they need to have a number-average molecular weight $\overline{\mathbf{M}}_{n}>30,000$ [30]. Both of the OctSn-DEG-SnOct-initiated copolymers in Table 1 have $\overline{\mathbf{M}}_{\mathrm{n}}$ values above this limit.

\subsubsection{Thermal Analysis}

Thermal properties of the $\mathrm{P}(\mathrm{LL}-\mathrm{co}-\mathrm{CL})$ copolymers were investigated by a combination of DSC and TGA. The results are summarized in Table 2 for copolymers prepared using both the OctSn-DEG-SnOct and $\mathrm{Sn}(\mathrm{Oct})_{2}$ initiators. The DSC data was derived from re-heating (2nd) scans following intermediate fast cooling so that the copolymer samples were all in an 
identical quenched amorphous state to enable comparison of their transition temperatures and crystallizabilities. As seen in Table 2, while the various transition and decomposition temperatures are quite similar, the significantly higher $\Delta \mathrm{H}_{\mathrm{c}}$ and $\Delta \mathrm{H}_{\mathrm{m}}$ values from the OctSnDEG-SnOct initiator suggest that it gives rise to a more crystallizable copolymer, possibly due to longer average LL sequence lengths and/or less transesterification. This in turn can be interpreted in terms of the effect that the initiator structure and, in particular, the chemical and steric environment of the Sn-O bond (active site) has on the initiator's reactivity. Greater crystallizability is considered to be advantageous for fiber processing since it leads to enhanced fiber tensile strength.

Table 2. DSC and TGA thermal analysis data of the P(LL-co-CL) copolymers synthesized using OctSn-DEG-SnOct and $\mathrm{Sn}(\mathrm{Oct})_{2}$ as initiators.

\begin{tabular}{cccccccc}
\hline Initiator & $\begin{array}{c}\text { Initiator } \\
\text { Conc. } \\
(\mathrm{mol} \%)\end{array}$ & $\begin{array}{c}\mathrm{DSC} \\
\mathrm{T}_{\mathrm{g}} \\
\left({ }^{\circ} \mathrm{C}\right)\end{array}$ & $\begin{array}{c}\mathrm{DSC} \\
\mathrm{T}_{\mathrm{c}} \\
\left({ }^{\circ} \mathrm{C}\right)\end{array}$ & $\begin{array}{c}\Delta \mathrm{H}_{\mathrm{c}} \\
(\mathrm{J} / \mathrm{g})\end{array}$ & $\begin{array}{c}\mathrm{DSC} \\
\mathrm{T}_{\mathrm{m}} \\
\left({ }^{\circ} \mathrm{C}\right)\end{array}$ & $\begin{array}{c}\mathrm{DSC} \mathrm{H}_{\mathrm{m}} \\
(\mathrm{J} / \mathrm{g})\end{array}$ & $\begin{array}{c}\mathrm{TGA}_{\mathrm{d}} \\
\left({ }^{\circ} \mathrm{C}\right)\end{array}$ \\
\hline$[\mathrm{Sn}(\mathrm{Oct})]_{2} \mathrm{DEG}$ & 0.01 & 29 & 120 & 6.8 & 156 & 11.0 & 225 \\
{$[\mathrm{Sn}(\mathrm{Oct})]_{2} \mathrm{DEG}$} & 0.02 & 28 & 119 & 6.7 & 158 & 15.1 & 235 \\
$\mathrm{Sn}(\mathrm{Oct})_{2}$ & 0.01 & 29 & 122 & 2.4 & 155 & 6.5 & 230 \\
$\mathrm{Sn}(\mathrm{Oct})_{2}$ & 0.02 & 22 & 104 & 2.5 & 146 & 8.6 & 224 \\
\hline
\end{tabular}

DSC data taken from 2 nd heating scan $\left(10^{\circ} \mathrm{C} / \mathrm{min}\right)$ after fast cooling $\left(200^{\circ} \mathrm{C} / \mathrm{min}\right)$

$\mathrm{T}_{\mathrm{g}}=$ glass transition temperature (mid-point)

$\mathrm{T}_{\mathrm{c}}=$ cold crystallization temperature (peak minimum)

$\Delta \mathrm{H}_{\mathrm{c}}=$ heat of crystallization ( $\propto$ crystallization peak area)

$\mathrm{T}_{\mathrm{m}}=$ melting temperature (peak maximum)

$\Delta \mathrm{H}_{\mathrm{m}}=$ heat of melting $(\propto$ melting peak area)

$\mathrm{T}_{\mathrm{d}}=$ thermal decomposition temperature (initial weight loss)

With reference to Table 2, it should be mentioned here that, although the $\mathrm{T}_{\mathrm{g}} \mathrm{s}$ are given as single temperatures, they are in fact the estimated mid-points of $T_{g}$ ranges which can be as wide as $10-20^{\circ} \mathrm{C}$. Apart from the nature of the $\mathrm{T}_{\mathrm{g}}$ transition itself, the main reason for such 
broad transitions is the copolymer's compositional heterogeneity which, in turn, can be traced back to the difference in the LL and CL monomer reactivity ratios previously mentioned. Therefore, the $T_{g}$ values in Table 2 should be viewed with this variation in mind.

Meanwhile, the TGA data in Table 2 shows thermal decomposition temperatures, $\mathrm{T}_{\mathrm{d}}$, $60-70^{\circ} \mathrm{C}$ higher than the melting temperatures, $\mathrm{T}_{\mathrm{m}}$. This gives a reasonably wide temperature range within which melt processing can be safely carried out. It is also worth noting here that this highlights another, often unmentioned, role of the CL units in the copolymer. In addition to flexibilizing the copolymer chain, which is their main purpose, they also serve to widen the melt processing range relative to PLL by both lowering $T_{m}$ and increasing $T_{d}$. This is because CL units are more thermally stable than LL units, as exemplified by the fact that PCL has a much higher $T_{d}$ than PLL even though it has a much lower $T_{m}$.

\subsection{Fiber Processing and Testing}

\subsubsection{Melt Spinning}

When the DSC and TGA thermograms are considered together, as shown in Figure 9, they are able to define the processing range for melt spinning. As a general rule, the optimum melt spinning temperature is usually taken to be the minimum temperature above $\mathrm{T}_{\mathrm{m}}$ (from DSC) which gives a suitable melt rheology and which is far enough below the initial weight loss temperature (from TGA) to minimize any thermal degradation due to, for example, transesterification in the melt state. Transesterification can be either intra- or intermolecular, although intermolecular is statistically the more probable. Whereas the main effect of intermolecular transesterification is merely to widen the molecular weight distribution, intramolecular is more damaging since it decreases the average molecular weight. Thus, minimizing both the temperature and the time for melt spinning is an important consideration in the fiber processing of polyesters. 


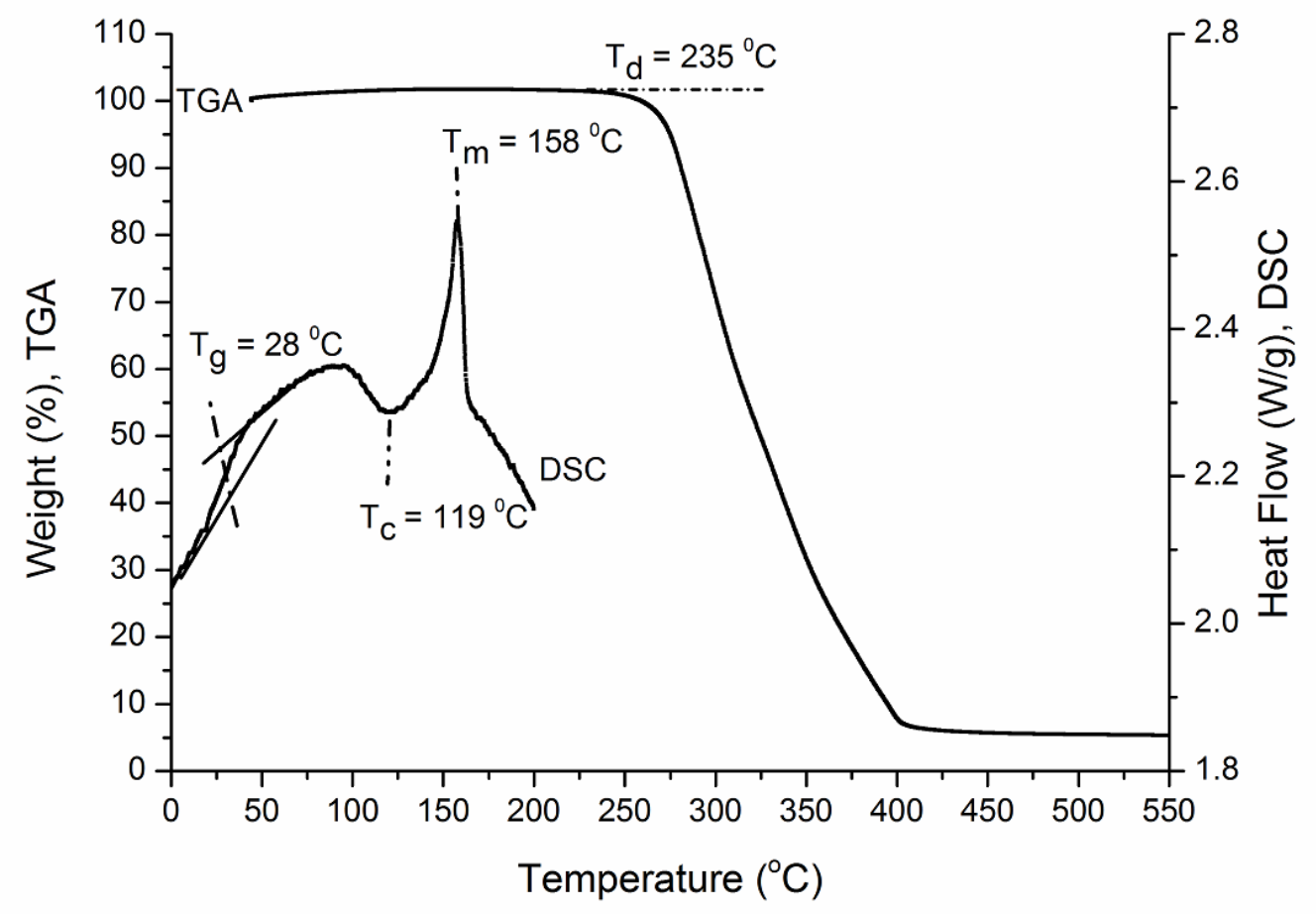

Fig. 9. DSC and TGA thermograms on the same temperature scale of the P(LL-co-CL) copolymer synthesized using $0.02 \mathrm{~mol} \%$ OctSn-DEG-SnOct as initiator.

Another important consideration in melt spinning is the effect of moisture. Polyesters are particularly susceptible to hydrolysis when in contact with moisture at high temperature. Since hydrolysis leads to random chain scission, the presence of moisture can have a drastic effect on molecular weight. Therefore, it was essential in this work that the copolymer was rigorously dried prior to melt spinning and that the processing operation was carried out in a humidity-controlled environment. Fast cooling of the extruded fiber as it emerged from the spinneret into the cool room air was also advantageous.

In this work, all of the copolymers in Tables 1 and 2 could be melt spun into good quality monofilament fibers. However, based on the DSC results in Table 2, the copolymer initiated by $0.02 \mathrm{~mol} \%$ OctSn-DEG-SnOct was chosen for further study due to having the highest $\Delta \mathrm{H}_{\mathrm{m}}$ (crystallizability) value. From its DSC and TGA thermograms in Figure 9, a 
melt spinning temperature in the range of $160-165^{\circ} \mathrm{C}$ was found to give the best results in terms of smooth melt extrusion and a stable filament line.

As mentioned previously, the as-spun fiber was purposely obtained with a largely amorphous and unoriented morphology so that the required semi-crystalline, oriented morphology could be built into it through a series of controlled off-line hot-drawing and fixed annealing steps. Both hot-drawing and annealing are time and temperature-dependent processes which have profound effects on matrix morphology and hence fiber properties. Hot-drawing, which requires a limited but not excessive amount of chain mobility, needs to be carried out at a temperature above the glass transition temperature, $\mathrm{T}_{\mathrm{g}}$, and so in this work temperatures of 40,55 and $70^{\circ} \mathrm{C}$ were employed and the results compared by tensile testing. Similarly, the temperature-time conditions for fixed annealing, which also needed to be carried out above $\mathrm{T}_{\mathrm{g}}$, were also varied. Based on the tensile test results, as described in the following section, the highest fiber tensile strength was obtained after a 1st hot-drawing at $70{ }^{\circ} \mathrm{C}$ followed by fixed annealing at $50{ }^{\circ} \mathrm{C}$ for $3 \mathrm{hrs}$ and a 2 nd hot-drawing at $70{ }^{\circ} \mathrm{C}$.

\subsubsection{Tensile Testing}

Tensile testing of the P(LL-co-CL) fiber at the various stages of its processing was carried out in accordance with the European Pharmacopoeia 5.0 Test Method for synthetic absorbable monofilament sutures [25] using bollard-type sample grips, a $100 \mathrm{~N}$ load cell, an initial gauge length of $40 \mathrm{~mm}$ and a crosshead speed of $80 \mathrm{~mm} \mathrm{~min}^{-1}$ (initial strain rate = $200 \% \min ^{-1}$ ). The stress-strain curves of the fiber are shown in Figure 10 and reflect the successive changes in morphology brought about by hot-drawing and annealing. Each tensile test was carried out on a minimum of 5 test specimens. The stress-strain curves in Figure 10 are those which were considered to be the most representative for each sample. 
As shown in Figure 10 (left), the most suitable temperature for the 1st hot-drawing, based on the fiber's tensile strength (stress at break), was found to be $70{ }^{\circ} \mathrm{C}$. Above this temperature, the fiber started to become too soft. Following this 1st hot-drawing, the tensile strength increased dramatically, mainly due to increased molecular orientation but also to some stress-induced crystallization. In Figure 10 (right), fixed annealing at $50{ }^{\circ} \mathrm{C}$ for $3 \mathrm{hrs}$ then allowed molecular relaxation to occur resulting in a further increase in tensile strength. However, the main purpose of fixed annealing was to stabilize the hot-drawn morphology through molecular relaxation so that the fiber could be drawn again to a higher draw ratio. Finally, following the 2nd hot-drawing, the fiber's tensile strength increased to $344 \mathrm{MPa}$ which was found to be comparable with commercial PDS ${ }^{\circledR}$ absorbable monofilament sutures of similar diameter (size 2-0) under identical test conditions. This size 2-0 was targeted since it is the suture size used in general surgery for bowel repair, a surgical procedure for which absorbable monofilaments are routinely used. The various physical and mechanical properties associated with the stress-strain curves in Figure 10 are summarized in Table 3.
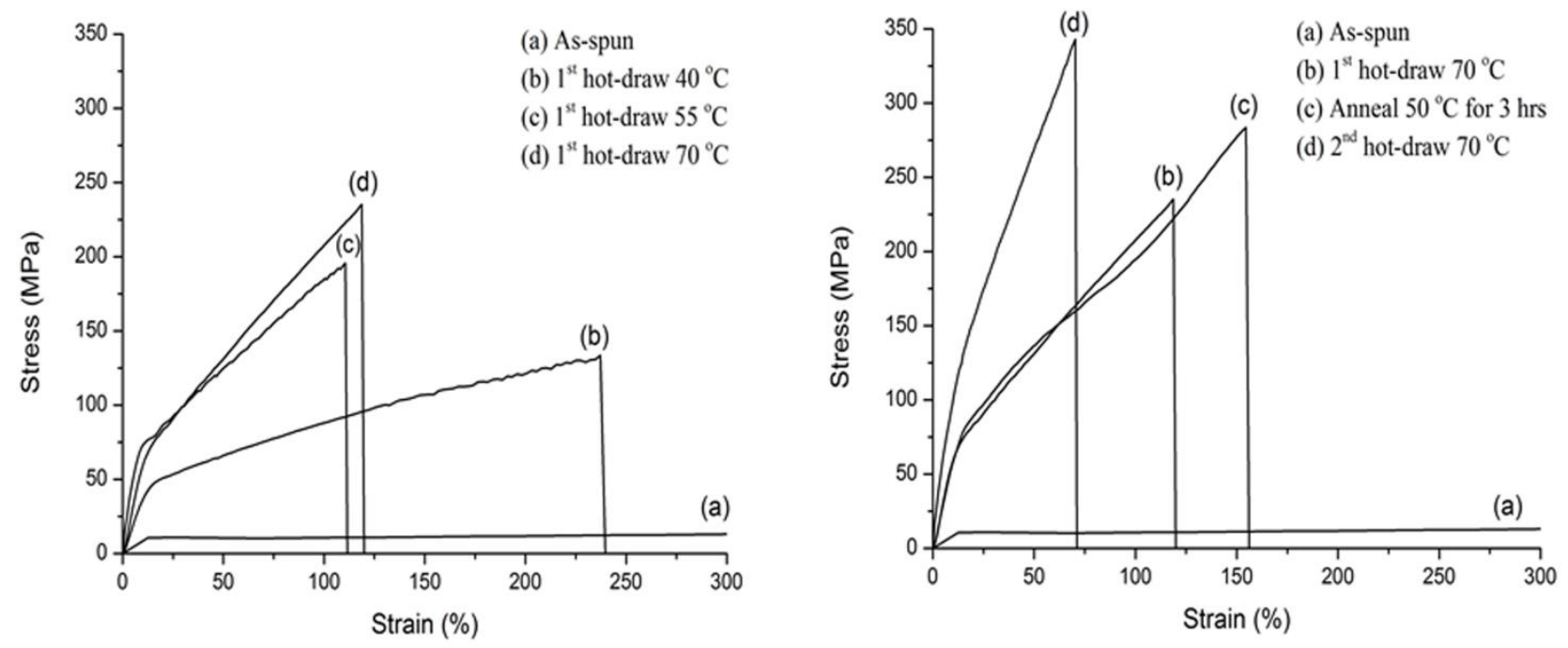

Fig. 10. Stress-strain curves of the P(LL-co-CL) fiber showing (left) the effects of the $1^{\text {st }}$ hotdraw temperature and (right) the sequence of effects at the various stages of processing. Sequence: As-spun $\rightarrow 1^{\text {st }}$ hot-draw $\rightarrow$ annealing $\rightarrow 2^{\text {nd }}$ hot-draw 
Table 3. P(LL-co-CL) monofilament fiber physical and tensile properties at the various stages of its processing.

\begin{tabular}{|c|c|c|c|c|c|}
\hline $\begin{array}{c}\text { Fiber at the } \\
\text { various stages } \\
\text { of processing }\end{array}$ & $\begin{array}{c}\text { Average } \\
\text { diameter } \\
(\mathrm{mm})\end{array}$ & $\begin{array}{l}\text { Draw } \\
\text { ratio } \\
\\
(\lambda)\end{array}$ & $\begin{array}{c}\text { Stress } \\
\text { at break } \\
(\mathrm{MPa})\end{array}$ & $\begin{array}{c}\text { Elongation } \\
\text { at break } \\
(\%)\end{array}$ & $\begin{array}{c}\text { Initial } \\
\text { modulus } f \\
(\mathrm{MPa})\end{array}$ \\
\hline As-spun ${ }^{b}$ & 0.80 & - & 25 & 1368 & 85 \\
\hline $1^{\text {st }}$ Hot-draw at $40^{\circ} \mathrm{C}^{b}$ & 0.52 & 5.1 & 134 & 239 & 357 \\
\hline $1^{\text {st }}$ Hot-draw at $55^{\circ} \mathrm{C}^{b}$ & 0.47 & 5.3 & 196 & 111 & 911 \\
\hline $1^{\text {st }}$ Hot-draw at $70^{\circ} \mathrm{C}^{b}$ & 0.32 & 5.7 & 235 & 119 & 633 \\
\hline As-spun ${ }^{c}$ & 0.80 & - & 25 & 1368 & 85 \\
\hline $1^{\text {st }}$ Hot-draw at $70^{\circ} \mathrm{C}^{c}$ & 0.32 & 5.7 & 235 & 119 & 633 \\
\hline Anneal at $50{ }^{\circ} \mathrm{C}$ for $3 \mathrm{hrs}{ }^{c}$ & 0.32 & 5.7 & 284 & 155 & 618 \\
\hline $2^{\text {nd }}$ Hot-draw at $70{ }^{\circ} \mathrm{C}^{c}$ & 0.26 & 8.3 & 344 & 70 & 1173 \\
\hline
\end{tabular}

${ }^{a}$ Sequence: as-spun $\rightarrow 1^{\text {st }}$ hot-draw $\rightarrow$ anneal $\rightarrow 2^{\text {nd }}$ hot-draw

${ }^{b}$ Data from Fig. 10 (left)

${ }^{c}$ Data from Fig. 10 (right)

${ }^{d}$ Relative to the as-spun fiber

${ }^{e}$ Stress at break $=$ tensile strength

${ }^{f}$ Measured manually from the initial slope

\section{Conclusions}

The results described here have shown that $\mathrm{P}(\mathrm{LL}-\mathrm{co}-\mathrm{CL})$ with a ratio of $\mathrm{LL}: \mathrm{CL}=75: 25 \mathrm{~mol}$ $\%$ obtained using the liquid OctSn-DEG-SnOct initiator gave higher molecular weights than the conventional $\mathrm{Sn}(\mathrm{Oct})_{2}$ initiator at the same mol \% concentration. The molecular weights were also more consistent from batch to batch. The P(LL-co-CL) copolymers could be melt spun into monofilament fibers of uniform diameter with mechanical properties, in particular the balance between strength and flexibility, which could be tailored to requirements by sequential off-line hot-drawing and annealing steps. In this way, the fiber's morphology (molecular orientation and crystallinity) could be effectively controlled and changes monitored throughout the various stages of processing. However, it can be appreciated that a 
multi-step spinning process such as this is only commercially viable for the small-scale batch production of high-cost speciality fibers such as those used in suture applications.

In conclusion, by developing a better understanding of (a) the various factors affecting initiator efficiency during synthesis and (b) the changes taking place at the molecular level during processing, monofilament fibers with controlled chemical and physical microstructure can be obtained. This control is essential if the stringent property requirements demanded of sutures are to be met. Based on the results described here, it is considered that $\mathrm{P}(\mathrm{LL}-\mathrm{co}-\mathrm{CL})$ copolymers synthesized using OctSn-DEG-SnOct as initiator have the potential to be developed further as materials for absorbable monofilament sutures. However, due to their relatively hydrophobic structure compared with most commercial monofilaments, they are more likely to find use in surgical operations where slow suture absorption over a period of several months is required.

\section{Acknowledgements}

The authors wish to thank the Department of Chemistry, Faculty of Science, Chiang Mai University for providing the facilities used in this research and the National Metal and Materials Technology Center (MTEC), Thailand, and the National Research University Project under Thailand's Office of the Higher Education Commission for financial support. The first-named author (S.R.) also thanks the Rajamangala University of Technology Lanna for the provision of a research grant.

\section{References}

1. Hollinger, J. O., Ed., Biomedical Applications of Synthetic Biodegradable Polymers; CRC Press, Boca Raton, 1995.

2. Domb, A. J.; Kost, J.; Wiseman, D. M., Eds., Handbook of Biodegradable Polymers; Harwood, Amsterdam, 1997. 
3. Kumbar, S. G.; Laurencin, C. T.; Deng, M., Eds., Natural and Synthetic Biomedical Polymers; Elsevier, Burlington, 2014.

4. Auras, R.; Lim, L-T.; Selke, S. E. M.; Tsuji, H., Eds., Poly(lactic acid): Synthesis, Structures, Properties, Processing, and Applications; Wiley, Hoboken, 2010.

5. Baimark, Y.; Molloy, R.; Molloy, N.; Siripitayananon, J.; Punyodom, W.; Sriyai, M. J. Mater. Sci.: Mater. Med. 2005, 16, 699-707.

6. Tomihata, K.; Suzuki, M.; Oka, T.; Ikada, Y. Polym. Degrad. Stab. 1998, 59, 13-18.

7. Jung, Y.; Kim, S. H.; You, H. J.; Kim, S-H.; Kim Y. H.; Min, B. G. J. Biomater. Sci. Polym. Edn. 2008, 19, 1073-1085.

8. Srisa-ard, M.; Molloy, R.; Molloy, N.; Siripitayananon, J.; Sriyai, M. Polym. Int. 2001, 50, 891-896.

9. Ge, H.; Hu, Y.; Yang, S.; Jiang, X.; Yang, C. J. Appl. Polym. Sci. 2000, 75, 874-882.

10. Thapsukhon, B.; Thadavirul, N.; Supaphol, P.; Meepowpan, P.; Molloy, R.; Punyodom, W. J. Appl. Polym. Sci. 2013, 130, 4357-4366.

11. Jung, Y.; Lee, S-H.; Kim, S-H.; Lim, J. C.; Kim, S. H. J. Biomater. Sci. Polym. Edn. 2013, 24, 386-397.

12. Zhou, Z.; Liu, X.; Liu, L.; Liu, Q.; Yi, Q. Int. J. Polym. Mater. Polym. Biomater. 2008, 57, 1026-1035.

13. Kowalski, A.; Duda, A.; Penczek, S. Macromolecules 2000, 33, 689-695.

14. Kowalski, A.; Duda, A.; Penczek, S. Macromolecules 2000, 33, 7359-7370.

15. Stridsberg, K. M.; Ryner, M.; Albertsson, A-C., in Degradable Aliphatic Polyesters, Albertsson, A-C., Ed., Adv. Polym. Sci. 2002, 157, 41-65.

16. Dechy-Cabaret, O.; Martin-Vaca, B.; Bourissou, D., in Handbook of Ring-Opening Polymerization, Dubois, P.; Coulembier, O.; Raquez, J-M., Eds., Chap. 10, Wiley-VCH, Weinheim, 2009.

17. Jelonek, K.; Kasperczyk, J.; Li, S.; Dobrzynski, P.; Janeczek, H.; Jarzabek, B. Biomed. Res. Int. 2013, 2013, Article ID 607351, 11 pages, doi: 10.1155/2013/607351.

18. Chittawatanarat, K.; Chotirodniramit, N.; Chandacham, K.; Molloy, R.; Laokul, C. J. Med. Assoc. Thai. 2010, 93, 123-127.

19. Jin, J.; Park, M.; Regarajan, A.; Zhang, Q.; Limburg, S.; Joshi, S. K.; Patel, S.; Kim, H. T.; Kuo, A.C. Regen. Med. 2012, 7, 799-806.

20. Thapsukhon, B.; Thadavirul, N.; Supaphol, P.; Meepowpan, P.; Molloy, R., Punyodom, W. J. Appl. Polym. Sci. 2013, 130, 4357-4366. 
21. Sriputtirat, S.; Boonkong, W.; Pengprecha, S.; Petsom, A.; Thongchul, N. Adv. Chem. Engineer. Sci. 2012, 2, 15-27.

22. Jung, Y.; Kim, S. H.; You, H. J.; Kim, S-H.; Kim, Y. H.; Min, B. G. J. Biomater. Sci. Polym. Edn. 2008, 19, 1073-1085.

23. Daranarong, D.; Thapsukhon, B.; Wanandy, N. S.; Molloy, R.; Punyodom, W.; Foster, L. J. R. Polym. Int. 2014, 63, 1254-1262.

24. Thapsukhon, B.; Daranarong, D.; Meepowpan, P.; Suree, N.; Molloy, R.; Inthanon, K.; Wongkham, W.; Punyodom, W. J. Biomater. Sci. Polym. Edn. 2014, 25, 1028-1044.

25. European Pharmacopoeia 5.0, $5^{\text {th }}$ Edn., Vol. 1, Sutures, Sterile Synthetic Absorbable Monofilament, Council of Europe, 2004, 880.

26. Morrison, J. S.; Haendler, H. M. J. Inorg. Nucl. Chem. 1967, 29, 393-400.

27. Gsell, R.; Zeldin, M. J. Inorg. Nucl. Chem. 1975, 37, 1133-1137.

28. Kleawkla, A.; Suksomran, W.; Charuchinda, A.; Molloy, R.; Naksata, W.; Punyodom, W. J. Solid Mech. Mater. Eng. 2007, 1, 613-623.

29. Dumklang, M.; Pattawong, N.; Punyodom, W.; Meepowpan, P.; Molloy, R.; Hoffman, M. Chiang Mai J. Sci. 2009, 36, 136-148.

30. Siripitayananon, J.; Molloy, R.; Bunkird, S.; Kleawkla, A.; Panjakha, R.; Chooprayoon, P. Int. Polym. Proc. 2008, XXIII, 161-167.

31. Grijpma, D. W.; Pennings, A. J. Polym. Bull. 1991, 25, 335-341.

32. Channuan, W.; Siripitayananon, J.; Molloy, R.; Sriyai, M.; Davis, F. J.; Mitchell, G. R. Polymer 2005, 46, 6411-6428. 